\title{
The Research on Colleges' Tuition Management System Development Based on Web
}

\author{
Wenzhong $\mathrm{XIA}^{1}$, Fengyun LIU*², Chunhong WU ${ }^{3}$ \\ ${ }^{1,2,3}$ Zhangjiakou Vocational College of Technology, Zhangjiakou 075000, China \\ bfengyunliu@163.com
}

Keywords: Tuition Management; B/S Structure; Web Technology

\begin{abstract}
Along with our country socialist market economic system gradually establish and perfect the education system of our country, especially the higher education system, and the corresponding reform. Gradually establish a government macro management, school faces the society run independently of the new system. College enrollment system reform, also brought the recruitment of students scale increases, college recruit students, enrollment situation, admissions category, cultivation method is becoming more and more complicated and diversified. All these prompt charge items are increasing, the difficulty and complexity increase, to the charge work brought huge workload, and work for college students is facing severe challenges.
\end{abstract}

\section{Introduction}

To improve safety performance system, this system is to expand further, put forward the role based access control mechanism, thus for each related department to provide different related data, data security, realize the connection with school related departments. And through the intelligent analysis data to provide decision data for the work [1]. The main purpose of this paper is to design a set of functional and effective college students' tuition management system, under the existing campus network environment, using $\mathrm{B} / \mathrm{S}$ structure to achieve a set of charging management system based on Web, accounting, management, to improve school students' tuition. At the same time, the charging information and other information through the campus network platform, can do all kinds of query statistics.

To build a set of scientific and efficient network charge system. And the system implementation on the school campus network platform to realize this topic. By means of function of each function test method for each module function test, safety test, the system performance test. The test results show that the project design is reasonable, safe and efficient. This topic through in-depth analysis, the reasonable design for universities to develop their own charge system to provide the feasibility scheme based on campus network, for the construction of college network charge system security provides a technical way. Therefore, the development of the role based access control charging network management system, college students will not only make the university tuition management onto a new stage, and reform the traditional accounting system, is a beneficial attempt in the new period.

\section{System related key technologies}

With the development of computer software development technology and network technology, more and more people using B/S software architecture for software development, B/S is called the Browser/Server or Browser/Server mode, is a kind of improvement of C/S structure, the system only need one Server, the client uses the Browser mode, people just need to access the WWW Browser, you will get what they need to text, video, images and other services, the WEB Server through some technology and the database connection, a large amount of data stored in the database. In $\mathrm{B} / \mathrm{S}$ structure is mainly by the browser by sending a request to a Web service layer and Web service layer after the transaction will request sent to the backend database, background database on the requested data in the data processing, then the processed data of concrete on the Web server to resend it to the browser display [2-3]. B/S three - tier architecture is to in figure 1. 


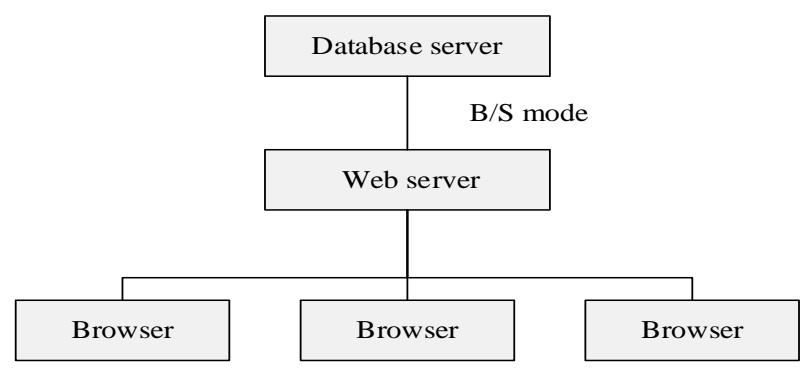

Figure 1. System structure of B/S

With the large increase in the rapid development of science and technology, network information, visit the Web site requires users to increase the speed, so that the database access technology more and more and more customers expect the database link concerns the process of technology access, ADO database access technology. Networks are more and more enterprises and customers trust and praise [4]. ADO. Net data access technology architecture shown in Figure 2.

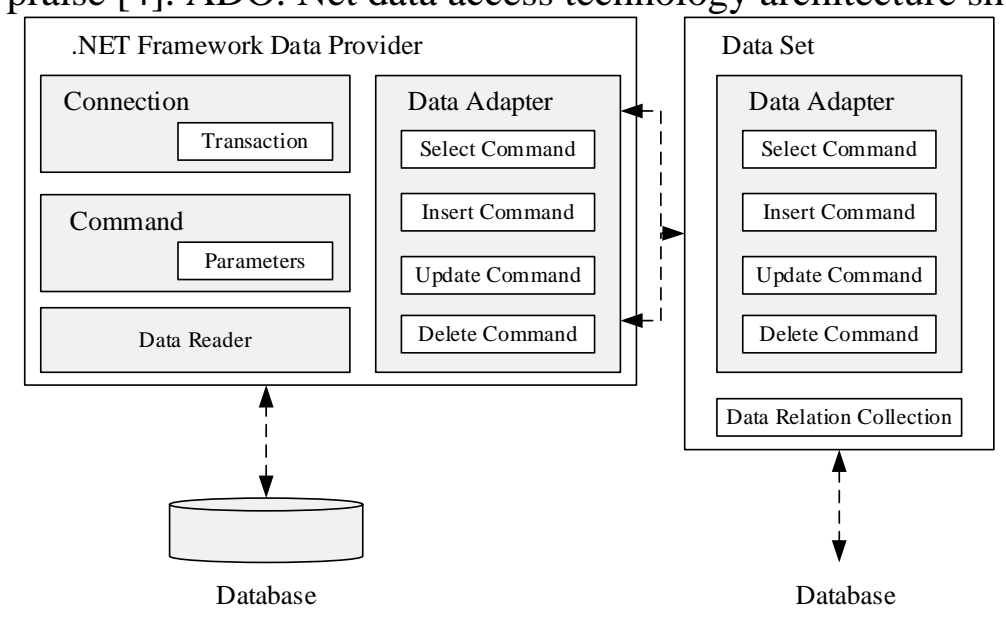

Figure 2. System structure of ADO.Net

\section{College tuition management system requirements analysis}

University tuition management system design and the main purpose of financial department in colleges and universities is convenient to manage school information, allow the architecture to support existing or subsequent development of content management related applications, can support in the form of a unified, safe trans-regional, unstructured data sharing across systems, enhancing the application value of unstructured data [5]. Digital asset management platform is the basic requirement of stability and efficiency of the design of the platform to withstand a variety of business system, the request of the vast amounts of unstructured data. We carried on the detailed function module partition. System's overall function module as shown in figure 2. This topic is the structure of the design system including 9 sub modules: user control module, user management module, initialization module, standard dictionary management module, charge management module, query module, statistics module, the students change module and system maintenance module.

User management module is mainly basic registration information for user account management, user management and user rights management. User control module according to the different login user name to give the corresponding privileges, and open the user can use the function module, function block don't need.

Standard initialization module is used to realize the annual tuition receivables and accounts receivable amount of setup and initialization, contains professional initialization Settings, dormitory initialization Settings, tuition standard setting, receivable accounts required standard setting, books standard setting, miscellaneous fees receivable accounts receivable standards set up, and the corresponding initialization, and other functions. 
Dictionary management module is used to implement system of department, the management of information, such as professional, classes, students of the management, including professional management, class management, and student management.

Charging management module is a key link in the system, it's mainly includes the general charge pattern, batch charging, refund processing, to print the document. Query module, the module is mainly used for charging for all kinds of information query, including student information inquiry, students should check fees, students' lack of query, combination query, and other functions, each query results can directly print.

Statistics module is mainly used in charge of the accounting, the resulting statistical results, this can result in the creation form pattern for printing, also can generate more intuitive graphs, helps managers in management analysis.

Students change module's main function is the student information management, including the student's professional treatment, grade, suspension and resumption, dropped out of schooling, transfer treatment, graduation, etc.

System maintenance module is the auxiliary management part of the system, generally only licensed to system administrator. The module mainly includes the log import and export management, database information, data backup, restore, etc.

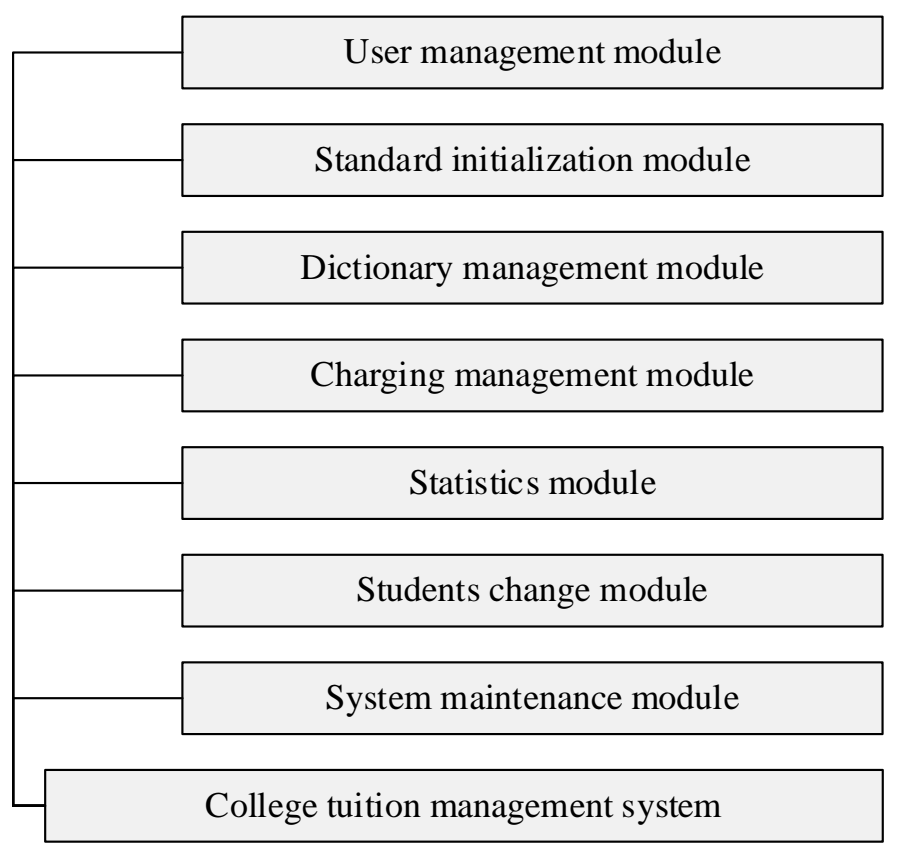

Figure 3. Function module college tuition management system

\section{Overall design of college tuition management system based in Web}

In view of the above analysis, the development and design of university tuition management system based on WEB. The purpose of the system design is to improve the work efficiency and reduce the workload of the finance department of colleges and universities, properly manage the charge information. The tuition management system has reliable concurrent processing capacity, combining with the cluster in the middle of the mechanism greatly reduce the possibility of collapse of middleware. Through the middleware to dynamic load balancing cluster technology, improve the system of concurrent processing, to meet the increase of the number of concurrent users, and can improve the overall throughput of the system, so as to achieve high availability, fault-tolerant application environment. System architecture diagram is shown in figure 3.

System end users by accessing WEB pages, through the Internet to receive the user's request, the user request submit to the system server business, the system server response is given. If the user submits the request to the database access operation, the server sends a request to the database, database processing is completed, the results back to the server, the server and the data results 
returned to the customer, the database to the customer request processing, to add, delete, and modify the data operation. After the treatment, the results back to the customer. Using this system architecture model, make universities charge management system to achieve the optimal processing speed, will be treated as different server deployment to a different place, to ensure that the data maintenance convenience for data statistics and control.

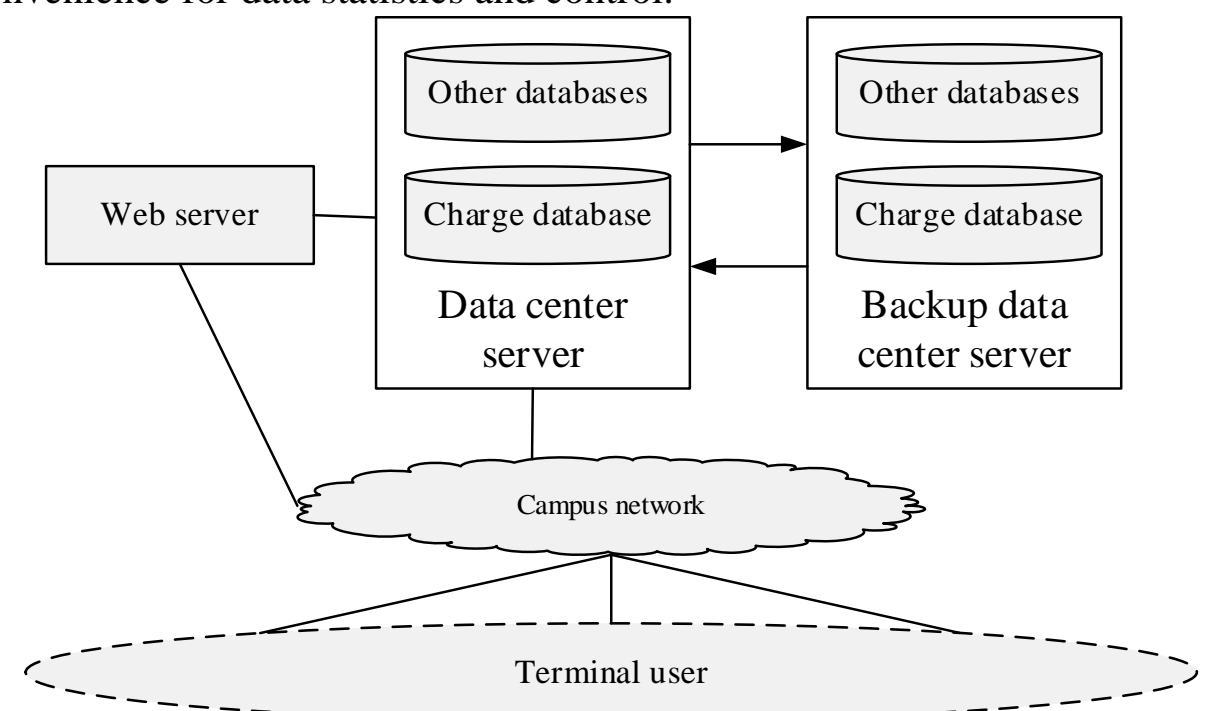

Figure 4. Overall structure of college tuition management system based in Web

\section{Conclusion}

With the improvement of the economic development of China and national quality, colleges and universities recruit students scale expands unceasingly in our country, the students category increased, to the college financial sector has brought the huge workload, and the university student fees information management has become diversified and complicated, how to effectively manage the student fees become main problems of university financial department. Therefore, to develop a perfect and efficient student tuition management system play a crucial role in the development of colleges and universities. In this paper, through the thorough analysis, the reasonable design for universities to develop their own tuition fees system provides feasibility scheme based on Web, design a set of functional and effective college students tuition management system, B/S structure was adopted to realize a set of charging management system based on Web, to improve school students tuition of accounting, management functions.

\section{Acknowledgements}

The Twelfth five-year Education Scientific Planning Project of Zhang Jiakou "The Development Research of the School fees Management System Based on Web” ,No.142892.

\section{References}

[1] C. Olston, and M. Najork: Foundations and Trends in Information Retrieval, Vol. 4(2010) No.3, p.175.

[2] M. Thelwall: Journal of Information Science, Vol. 27(2011) No.5, p. 319.

[3] H. Liu, J. Janssen, and E. Milios: Data \& Knowledge Engineering, Vol. 59(2009) No.2, p. 270.

[4] C. Bizer, J. Lehmann, and G. Kobilarov: Web Semantics: science, services and agents on the world wide web, Vol. 7(2012) No.3, p. 154.

[5] J.K. Batcheller, F. Reitsma: Computers, Environment and Urban Systems, Vol. 34(2010) 